\title{
Short-term hyperthermia at larval age reduces sucrose responsiveness of adult honeybees and can increase life span
}

\author{
Arne Kablau ${ }^{1,2}$, Stefan Berg $^{3}$, Benjamin RutschmanN ${ }^{4,5}$, Ricarda Scheiner ${ }^{1}$ \\ ${ }^{1}$ Behavioral Physiology \& Sociobiology, Biocenter, University of Würzburg, Am Hubland, 97074, Würzburg, Germany \\ ${ }^{2}$ Department of Veterinary Medicine, Institute of Veterinary Biochemistry, Freie Universität Berlin, Berlin, Germany \\ ${ }^{3}$ Institute for Bee Research and Beekeeping, Bavarian State Institute for Viticulture and Horticulture, Veitshöchheim, \\ Germany \\ ${ }^{4}$ Department of Animal Ecology and Tropical Biology, Biocenter, University of Würzburg, Würzburg, Germany \\ ${ }^{5}$ University of Würzburg, Würzburg, Germany
}

Received 9 May 2019 - Revised 31 October 2019 - Accepted 22 January 2020

\begin{abstract}
Honeybees are very sensitive to their breeding temperature. Even slightly lower temperatures during larval development can significantly affect adult behavior. Several devices which are employed for killing the honeybee ectoparasite Varroa destructor rely on short-term hyperthermia in the honeybee hive. The device used here applies $43.7^{\circ} \mathrm{C}$ for $2 \mathrm{~h}$, which is highly effective in killing the mites. We study how short-term hyperthermia affects worker brood and behavior of emerging adult bees. Sucrose responsiveness was strongly reduced after treatment of larvae early or late of larval development. Hyperthermia significantly enhanced life span, particularly in bees receiving treated early in larval development. To ask whether increased life span correlated with foraging performance, we used radio frequency identification (RFID). Onset and offset of foraging behavior as well as foraging trip duration and lifetime foraging effort were unaffected by hyperthermia treatment as prepupa.
\end{abstract}

\section{temperature / Varroa destructor / worker behavior / Apis mellifera / RFID}

\section{INTRODUCTION}

\section{Significance statement \\ Hyperthermia is an effective tool against Varroa destructor in honeybee hives. Sur- prisingly little is known on the effects of this treatment on honeybee workers. We show that hyperthermia treatment early in the lar- val stage can have a life-prolonging effect on worker bees without negative effects on foraging behavior. However, sucrose re- sponsiveness is reduced after the treatment.}

Corresponding author: R. Scheiner, ricarda.scheiner@uni-wuerzburg.de Manuscript editor: Yves Le Conte
The ectoparasitic mite Varroa destructor is the most important single driver of honeybee colony losses worldwide (Rosenkranz et al. 2010). The mites develop in drone and worker brood but prefer drone brood because of the lower temperature in the nest periphery and the longer development of drone brood (Kraus et al. 1998). $V$. destructor mites do not only debilitate honeybee development by feeding on their fat reserves (Ramsey et al. 2019), but can transmit a number of viruses which, for example, lead to the deformation of abdomen or wings (deformed wing virus, De Jong et al. 1982), or reduce lifetime (Schneider and Drescher 1987). Naturally, there is a great interest in methods to prevent these mites from growing and reproducing in honeybee colonies.

An alternative to chemical treatment of $V$. destructor mites, which has become quite 
popular in the last decades, is short-term hyperthermia treatment of honeybee brood. Bees and mites differ in their sensitivity for rising temperatures (Engels 1998). Hyperthermia is a method in which the whole bee colony or only the sealed brood combs are exposed to higher temperatures which are lethal for the mites but not fatal for honeybees, in particular for the brood $\left(41-44^{\circ} \mathrm{C}\right.$, Rosenkranz 1987; Engels 1998; Harbo 2000; Tabor and Ambrose 2001; for review, see Rosenkranz et al. 2010; Goras et al. 2015). Naturally, temperature preferences of honey bees also depend on the subspecies (Kovac et al. 2014). There are different hyperthermia devices on the market which employ the same principle but differ in their application. One of them is the Silent Future Tec Varroa Kill II@). We used this device to investigate effects of short-term hyperthermia early in honeybee development on adult worker bees.

Deviations from normal temperature during larval development can lead to altered phenotypes and behaviors, malformations, and increased mortality (Himmer 1932; Medina et al. 2018). Furthermore, it can have huge effects on adult behavioral performance such as dancing, learning and division of labor in honeybees (Tautz et al. 2003; Groh et al. 2004; Becher et al. 2009), on the color of emerging bees (DeGrandi-Hoffman et al. 1993), and on wing morphology (Ken et al. 2005). During the pupal phase, honeybees are particularly sensitive to shifts in temperature, because in this developmental period, the larval nervous system is completely remodeled to accommodate the changes in sensory and motor systems associated with the transition from a larva to an adult insect. Brood nest temperature is therefore tightly regulated by worker bees (Bujok et al. 2002; Kleinhenz et al. 2003; Fehler et al. 2007; Stabentheiner et al. 2010).

To ask whether hyperthermia treatment affects sensory responsiveness of adult honeybee workers, we tested their sucrose responsiveness. Individual sucrose responsiveness has been shown to be strongly correlated with non-associative and associative learning behavior (Scheiner et al. 1999, 2001a, b, 2003, 2004, 2005; Scheiner and Erber 2009; Behrends and Scheiner 2012), with responsiveness to pollen (Scheiner et al. 2004), and serves as a general indicator of the physiological state of the bee (Scheiner and Erber 2009; Scheiner et al. 2013).

Because brood nest temperature can have large effects on life expectancy and division of labor in honeybee workers (Becher et al. 2009), we also tested whether short-term hyperthermia would affect these parameters. With respect to division of labor, we focused on the initiation of foraging activity as the most drastic and best-studied change in worker behavior (Amdam and Amdam and Omholt 2003; Herb et al. 2012) using radio frequency identification (RFID) and looked for possible interactions between hyperthermia, onset of foraging, and life span.

\section{MATERIAL AND METHODS}

\subsection{Source of bees}

The experiments were performed in the summer of 2017 with colonies of Apis mellifera carnica. All colonies were maintained at the Bavarian State Institute for Viticulture and Horticulture, Institute for Bee Research and Beekeeping, Veitshöchheim, Germany.

\subsection{Age groups tested}

In the first experiment on sucrose responsiveness, we tested 13 age cohorts which had received hyperthermia treatment at different larval stages from early to late larval development. Because individual sucrose responsiveness is a robust indicator of the general physiological state of a honeybee (Scheiner et al. 2013), we chose this test to get a first impression of overall effects of hyperthermia on honeybees. In the subsequent experiment on mortality, we focused on the two age groups which showed the most dramatic effects of hyperthermia on sucrose responsiveness, i.e., bees treated on day 1 and those treated on day 11 of larval development, to ask if a reduced sucrose responsiveness is an indicator of a higher risk for mortality.

In the final experiment investigating the foraging activity of individual bees following hyperthermia treatment, we decided to focus on the age group in which hyperthermia significantly increased life span in both replicates, because we 
asked if a prolonged life span would reduce lifetime foraging activity. This was the group of bees which had received hyperthermia treatment very early in development, i.e., on day 1 .

\subsection{Hyperthermia treatment}

Treatments were performed with the Silent $\mathrm{Fu}-$ ture Tec Varroa Kill IIC (Figure 1a, b) and carried out in a box with eight frames. The Silent Future Tec Varroa Kill IIC was placed in the center of the hive to achieve an optimal air flow (Figure 1b). According to the manufacturer's instructions, the temperature gradually rose from approximately $20{ }^{\circ} \mathrm{C}$ until $43.7^{\circ} \mathrm{C}$, which was reached after $15-30 \mathrm{~min}$. This temperature was maintained for $108 \mathrm{~min}$, before temperature fell down gradually to ambient temperature. In each experiment, one frame with larvae of mixed or specific age was treated.

\subsection{Raising of bees}

In our first experiment analyzing sucrose responsiveness, we treated worker brood of mixed ages with hyperthermia. After hyperthermia treatment, treated brood combs and control brood combs were placed in a foster colony for rearing. Foster colonies were treated against Varroa destructor in advance to make sure that afterwards dead mites only came from heat-treated brood. From August on, we returned treated brood combs into the donor colonies, because foreign brood would have been destroyed otherwise. Control brood combs were kept under normal hive conditions and did not receive a hyperthermia treatment. After the brood cells were capped, the brood combs were transferred to an incubator $\left(34.5^{\circ} \mathrm{C}\right.$, $50-70 \%$ relative humidity) within a wooden cage with a window to observe when the first bees began to hatch. The cage was controlled daily.

After hatching, bees were marked with shellac and pigments according to their hatching date and group. Based on the hatching date, we calculated the age during which the treatment had been performed with the respective larvae. Marked bees and controls were transferred into a mini-plus colony unless stated otherwise. The mini-plus colony contained 12 frames (each $20 \mathrm{~cm}$ wide and $14 \mathrm{~cm}$ in height) in two boxes, one mated queen, and workers. After 1 week, control bees and treated bees were recollected from the hive and tested for their behavior.

\subsection{Quantification of individual sucrose responsiveness}

Individual sucrose responsiveness has proved to be a reliable indicator of the behavioral and physiological state of a honeybee (Scheiner et al. 2004; Rueppell et al. 2006; Becher et al. 2009; Behrends and Scheiner 2012). To identify at which larval age hyperthermia might have the strongest effects on honeybee behavior, we employed the sucrose responsiveness assay described elsewhere (Behrends and Scheiner 2010,
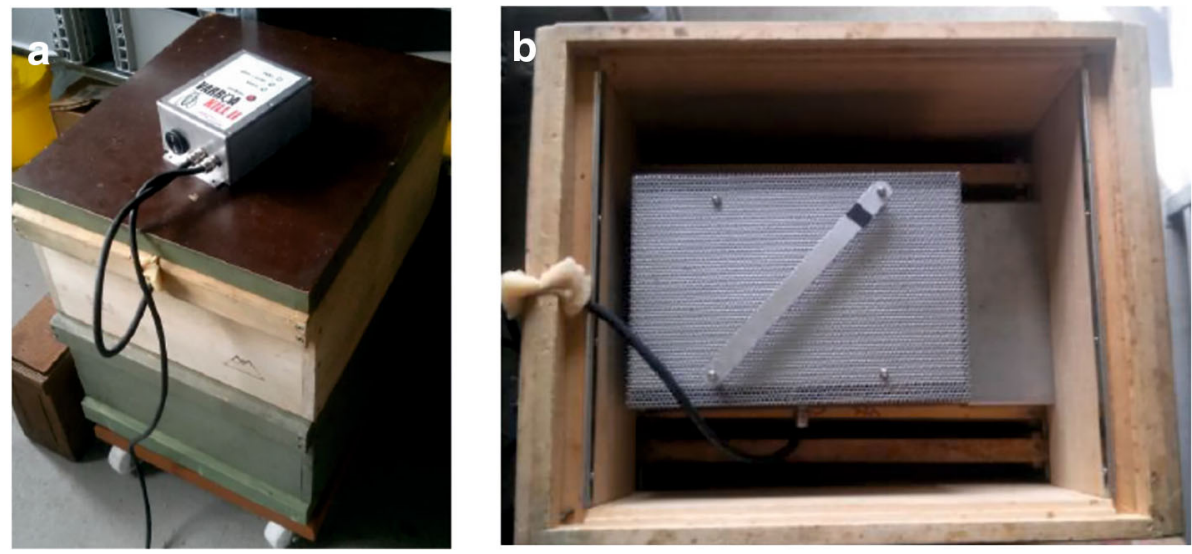

Figure 1. a The Silent Future Tec Varroa Kill II@ device placed inside a honeybee hive. b The heating unit of the Silent Future Tec Varroa Kill II@ is placed on top of brood combs. 
2012; Scheiner et al. 2013). In brief, 1-week-old bees (control bees and hyperthermia-treated bees) were collected from their colony and were immobilized and mounted individually. The experimenter was not blind to the treatment groups during preparations for the experiment, but bees from different treatment groups were placed in random order during testing. Then each bee was stimulated with a series of increasing sucrose concentrations at its antennae and the occurrence of the proboscis extension response was recorded for each concentration. The sum of responses to water and six different sucrose concentrations constitutes the gustatory response score (GRS) of a bee and is a measure for its overall responsiveness (Scheiner et al. 2013).

\subsection{Mortality}

For this experiment, we decided to focus on two stages in the development of bee brood: day 1 and day 11 , because they display two completely different developmental stages and because they showed the strongest effects of hyperthermia on sucrose responsiveness (see Section 3).

After hatching, 50 bees of each treatment group were placed into a cage with a piece of wax foundation on the back side. Bees had food ad libitum (Apiinvert@) (73\% sugar, 27\% water), mixture of honey/pollen). Cages were kept in an incubator at $30{ }^{\circ} \mathrm{C}$ (Himmer 1932; Paxton et al. 2007 ), relative humidity was held at $50-70 \%$ (OECD 1998). Mortality was recorded for 4 weeks. We analyzed two replicates of each treatment group (treatment on day 1 and on day 11 , both experiencing the same exposure time) and respective controls.

\subsection{Tracking of individual foraging behavior}

To quantify effects of hyperthermia treatment on lifetime foraging performance and to analyze onset and end of foraging as well as trip duration, we used RFID of individual foragers (MAJA Bundle Bee Identification System: iID2000 ISO15693 optimized, microsensys GmbH, Erfurt, Germany). For this purpose, we marked newly emerged bees individually with passive RFID tags and by color (Nunes-Silva et al. 2018). Each tag had a unique identification number. We placed two readers at the hive entrance, thereby allowing us to identify the direction of movement. We used a control group and a treatment group. In the

Table I. Age at larval treatment, number of bees tested for gustatory responsiveness, $Z$ value, and $P$ value of MannWhitney $U$ test

\begin{tabular}{lcccc}
\hline Age (days) & No control bees & No hyperthermia bees & $Z$ value & $P$ value \\
\hline 1 & 169 & 168 & 5.82 & $<0.0001$ \\
2 & 50 & 46 & 1.11 & 0.27 \\
3 & 45 & 37 & 4.19 & $<0.0001$ \\
4 & 33 & 51 & 0.14 & 0.89 \\
5 & 39 & 60 & 0.93 & 0.35 \\
6 & 46 & 53 & 1.80 & 0.07 \\
7 & 19 & 52 & 0.99 & 0.32 \\
8 & 29 & 95 & 2.31 & 0.02 \\
9 & 39 & 71 & 5.54 & $<0.0001$ \\
10 & 82 & 12 & 0.30 & 0.77 \\
11 & 96 & 88 & 10.17 & $<0.0001$ \\
12 & 47 & 48 & 0.41 & 0.68 \\
13 & 126 & 59 & 1.51 & 0.13 \\
\hline
\end{tabular}

Significant differences between groups are given in italics 
treatment group, bees had been treated with hyperthermia for $2 \mathrm{~h}$ at day 1 of larval development. This was the age group with the largest overall effects on behavior and life span. Bees were placed in a mini-plus-colony with two boxes. To make sure that the bees were accepted by the colony, we used thyme spirit to negate foreign odors and frame cages. Acceptance rate of the 200 RFID-tagged bees treated with hyperthermia and the 200 tagged control bees in the hive was about $50 \%$ and did not differ between hyperthermia-treated bees and controls $(P>0.05$, Fisher Exact Probability Test).

Bees which only left the hive once were excluded from analysis, because we assume they left the hive to die outside or were not accepted by the colony and were pushed outside. We defined a foraging trip as a bee being outside the hive for more than $180 \mathrm{~s}$. Initiation of foraging was defined as follows: when a bee left the hive for two trips on 1 day, this day was counted as day of initiation of foraging. Alternatively, when a bee left the hive for one trip on 1 day and for one or more trips on a subsequent day, the first day was counted as the day of onset of foraging. When more than 1 day lay between the first and the second foraging trips, the second day was regarded as onset of foraging. Further, we measured the duration of foraging trips per bee per day to get an estimate of flight intensity for the different treatment groups. We defined the end of foraging as the last time a bee was detected. If the bee was detected within the last 3 days of the experiment, data were censored in further statistical analysis regarding the end of foraging. Flight behavior was recorded for 56 days.

\subsection{Statistical analysis}

We evaluated results with SPSS 24.0 (IBM, Armonk, NY USA) and GraphPad PRISM 7 (GraphPad Software, La Jolla, USA). GRS of the different groups were not distributed normally $(P<$ 0.001, two-tailed Kolmogorov-Smirnov test). Hyperthermia-treated bees and control bees of the same treatment age were therefore compared for their GRS using two-tailed Mann-Whitney $U$ tests. Effects of hyperthermia treatment on responses to each sucrose concentration (scored as a binary response, i.e., full proboscis extension or not) were analyzed using binary logistic regression (log regr. generalized linear model, response variable: response to sucrose; predictor variable: treatment, link function: $g(\mu)=\log (\mu /(1-\mu)))$. For survival analysis between hyperthermia-treated bees and controls, we performed Kaplan-Meier statistics and log rank tests. These tests were also applied for comparing onset and end of foraging between the treatment groups. Duration of foraging trips during the lifetime of foragers was compared between the different treatment groups using repeated measurement analysis of variance (RM ANOVA), with day as withinsubject factor and treatment as between-subject factor. Lifetime foraging duration and lifetime foraging effort were compared between groups using ManWhitney $U$ tests, because data were not distributed normally. Acceptance rate of bees introduced in the hive was compared between treatment groups using Fisher Exact Probability Tests.

\section{RESULTS}

\subsection{Sucrose responsiveness}

When tested at the age of 1 week old, bees responded significantly less frequently to a series of increasing sucrose concentrations when they had experienced hyperthermia on day 1, 3, 8, 9, or 11 of their larval development, which resulted in significantly lower gustatory response scores (Figure 2a; day 1, egg: $Z=5.82, P<0.001$; day 3, hatching of egg: $Z=4.19, P<0.001$; day 8 , larva: $Z=2.31, P<0.05$; day 9 , larva: $Z=5.12$, $P<0.001$; day 11, prepupa: $Z=8.48, P<0.001$ ). This demonstrates that hyperthermia can reduce responsiveness to sugars, depending on time of treatment.

For a detailed picture of the effects of hyperthermia on sucrose responsiveness early in development (day 1) and late in larval development (day 11), we show the sucrose-concentrationresponse curves of the two treatment groups for adult bees (Figure 2b, c). All bees were generally more responsive to higher sucrose concentrations than to lower concentrations. Hyperthermiatreated bees were significantly less responsive than controls both when they had been treated on day 1 (Figure $2 \mathrm{~b} ; \chi^{2}=110.75, P<0.001$, log. regr.) or on day 11 (Figure $2 \mathrm{c} ; \chi^{2}=97.56$, $P<0.001)$. 

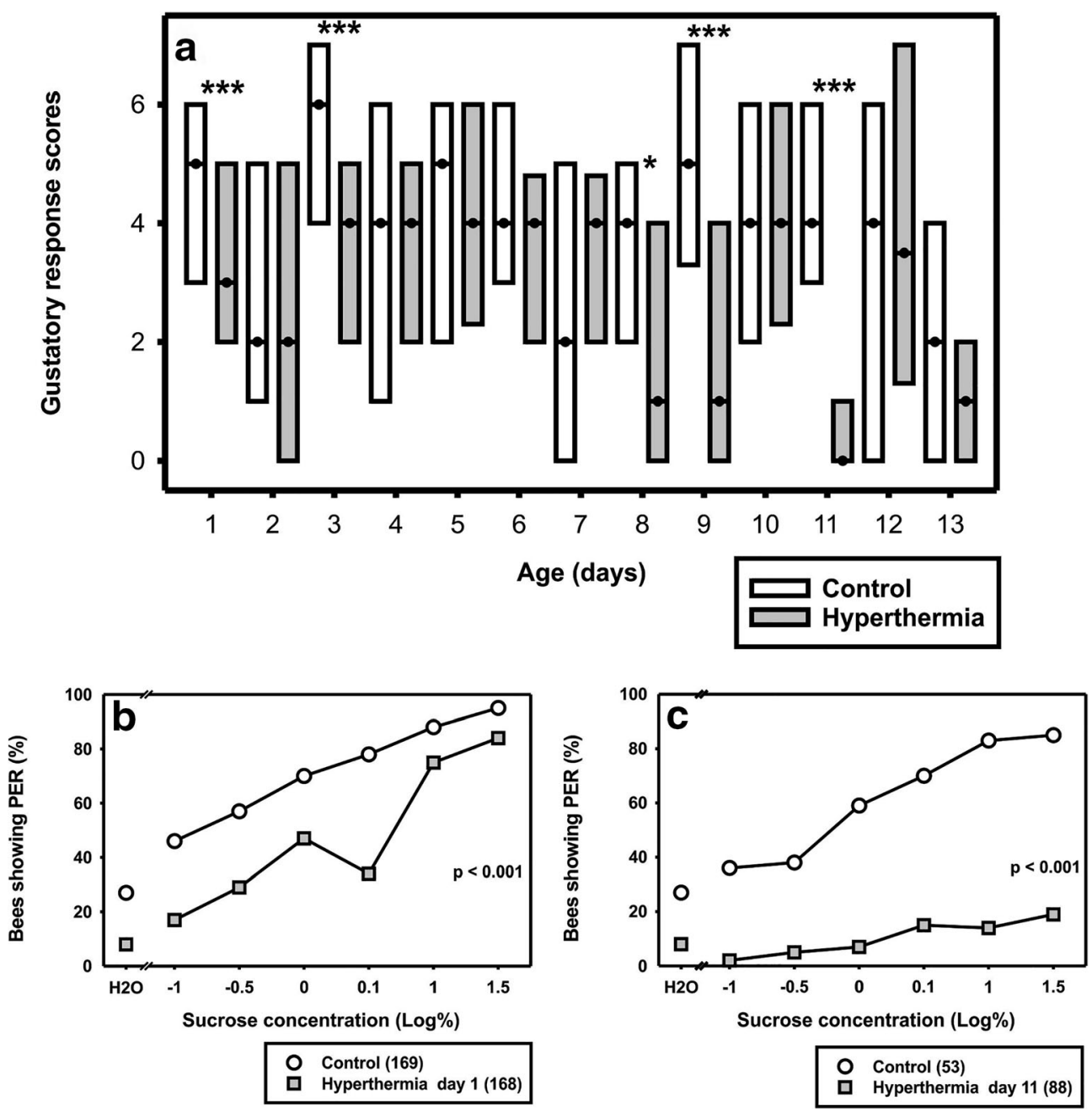

Figure 2. a Gustatory response scores (GRS) of control bees (white) and bees treated with hyperthermia at different larval stages (gray). All bees were between 6 and 8 days of age during testing for GRS. Median GRS, indicated by a dot, and 25 and 75\% quartiles (lower and upper lines, respectively) are displayed. Significant differences between the treatments per age cohort of treatment are indicated $(* P<0.05$, $* * * P \leq 0.001$, Mann-Whitney $U$ test). Further details on statistical results and number of bees see Table I. b, c Sucrose-concentration-response curves of bees treated with hyperthermia at day 1 (b) or at day 11 (c) of larval development (gray) and of control bees (white). Whereas control bees showed average responsiveness to water and increasing sucrose concentrations, responsiveness was strongly reduced in bees treated with hyperthermia on day 1 or day 11. Significant differences between groups are indicated by their $P$ values (log. regr.). Numbers of bees tested in each group are displayed in brackets behind treatment.

\subsection{Mortality}

Hyperthermia significantly affected mortality in caged bees. Both replicates treated with hyperthermia on day 1 ("H1") displayed a significantly enhanced life span (Figure 3a, b; $\chi^{2}=19.27$,
$P<0.001$ and $\chi^{2}=6.99, P<0.01, \log$ rank test). Hyperthermia treatment on day 11 ("H11") increased life span in one out of two replicates (Figure $3 \mathrm{c} ; \chi^{2}=6.18, P<0.05$ and Figure $3 \mathrm{~d}$; $\left.\chi^{2}=0.66, P>0.05\right)$. 
Day 1 treatment, replicate 1

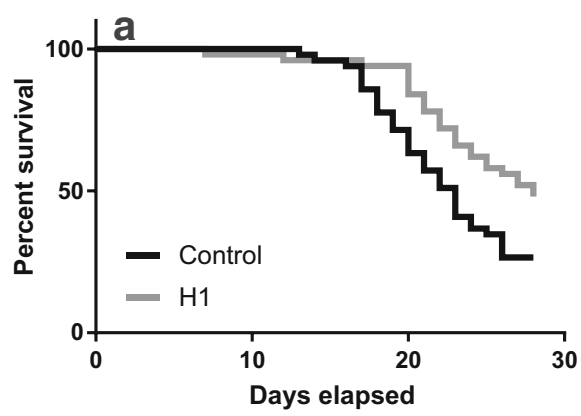

Day 11 treatment, replicate 1

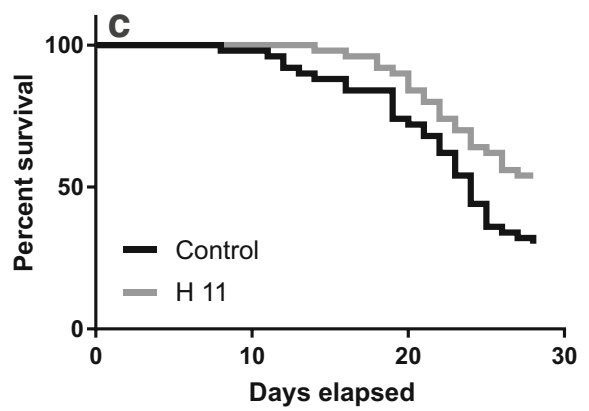

Day 1 treatment, replicate 2

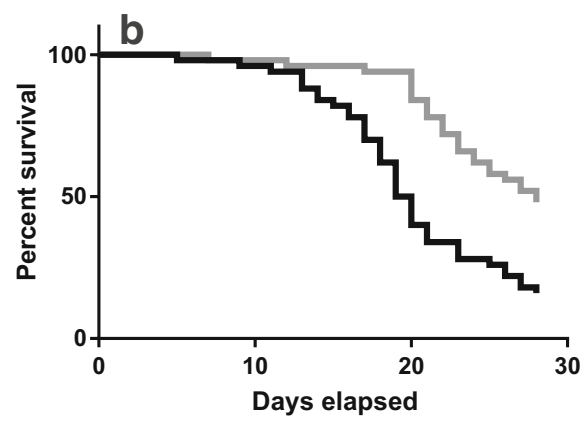

Day 11 treatment, replicate 2

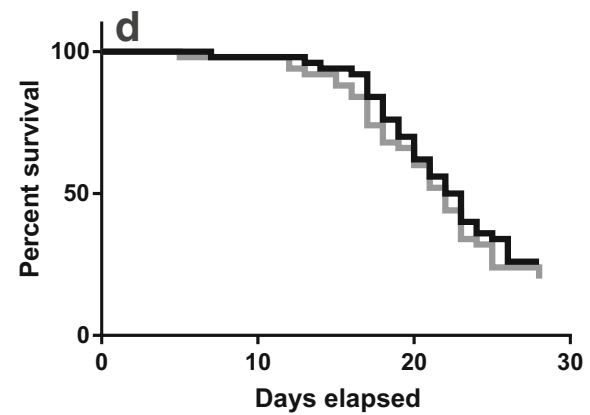

Figure 3. Survival of bees after early (day 1) or late (day 11) treatment of hyperthermia during pupal development. a , b Survival of control bees (black line, "control") and bees treated on day 1 (gray line, "H1") with hyperthermia in two replicates. c, d Survival of control bees and bees treated on day 11 ("H11") with hyperthermia in two replicates. In both replicates with 50 bees of each treatment, bees treated with hyperthermia on day 1 survived significantly longer than respective controls ( $P$ at least $<0.01, \log$ rank test). When hyperthermia treatment was applied on day 11 , survival was significantly longer than that of the control group in replicate $1(P<0.05)$ and did not differ from the control in replicate 2.

\subsection{Effects of hyperthermia on flight and foraging behavior}

Hyperthermia treatment did not affect the timing of the nurse-forager transition. Both hyperthermiatreated bees and control bees started flying out around day 6. Neither onset of flight nor end of foraging flights differed between hyperthermiatreated bees and controls (onset: Figure $4 \mathrm{a}, \chi^{2}=$ $0.14, P>0.05$; offset: Figure $4 \mathrm{~b}, \chi^{2}=0.11$, $P>0.05$, log rank test). Foraging life span also did not differ between the two groups (data not shown; $Z=1.37, n_{\text {control }}=134, n_{\text {hyperthermia }}=139$, $P>0.05$, two-tailed Mann-Whitney $U$ test).

In addition, duration of foraging flights over lifetime was not affected by treatment, although trip duration was significantly affected by time (treatment: $F_{(1,277)}=0.33, P>0.05$; time: $F_{(55,14.905)}=26.98, P<0.001$, RM ANOVA). Lifetime foraging effort, i.e., the total number of foraging flights per bee, was also unaffected by treatment (data not shown; $Z=0.03, n_{\text {control }}=$ $134, n_{\text {hyperthermia }}=139, P>0.05$; two-tailed Mann-Whitney $U$ test). These data suggests that hyperthermia at larval state has no effects on flight performance or lifetime foraging duration.

\section{DISCUSSION}

\subsection{Sucrose responsiveness}

Hyperthermia led to a reduced adult sucrose responsiveness when applied at different developmental stages. All of our bees tested were 

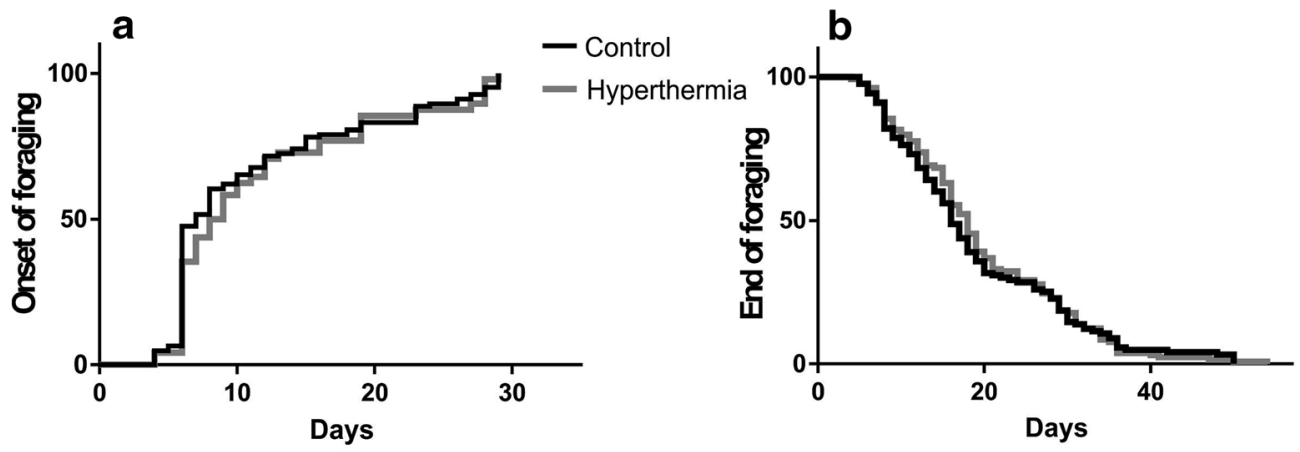

C

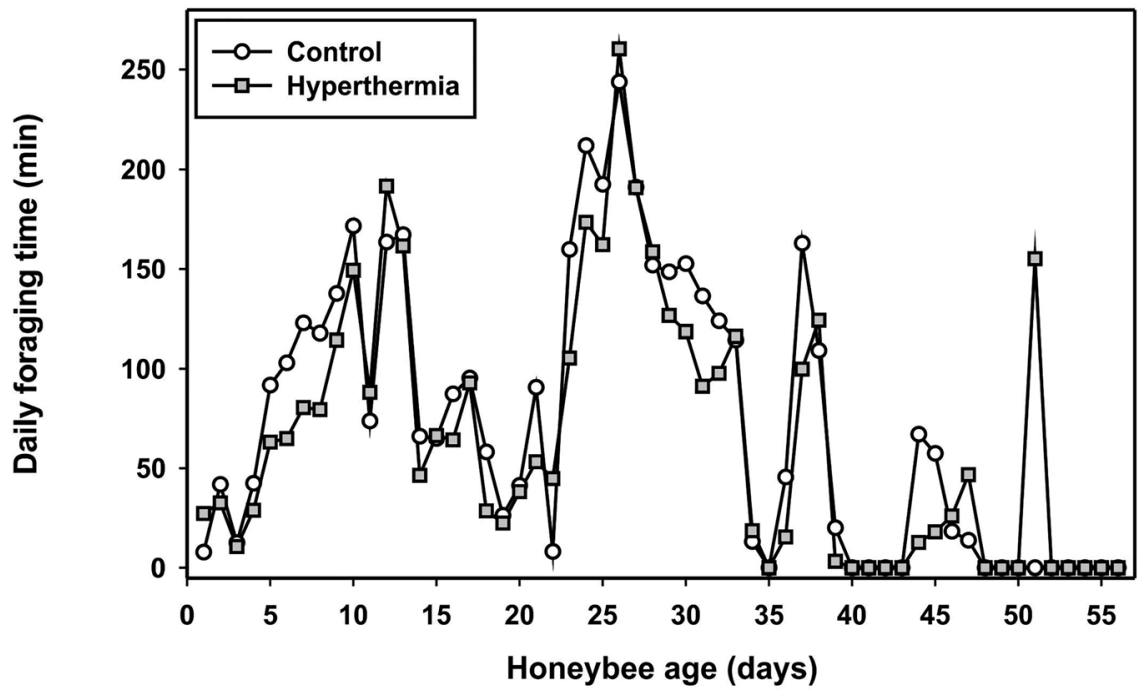

Figure 4. Onset of foraging (a) and end of foraging (b) in control bees (black line) and hyperthermia (day 11) treated bees (gray line). Both groups did not differ in the onset or end of foraging (Kaplan-Meier with log rank test $P>0.05$ ). c Trip duration of foragers treated with hyperthermia on day 1 (black) and control bees (gray). Mean trip durations are displayed. Trip duration did not differ between both treatment groups.

maintained in small colonies and had constantly access to food. We can therefore exclude the possibility that different treatment groups had different sucrose responsiveness due to hunger. Since sucrose responsiveness also varied in controls, comparisons are only appropriate between each control group and the corresponding hyperthermia group. Overall, there was only 1 day in which the sucrose responsiveness of the control bees showed the trend to be lower than that of the hyperthermia group. In all of the other comparisons, the hyperthermia group was either significantly less responsive than the control group or did not differ from the control (Figure 2a).
Sucrose responsiveness was specifically reduced when hyperthermia treatment was performed very early in development (i.e., day 1 or 3 ) or shortly before or at the beginning of the pupal stage (day 8,9 , or 11 ). In how far this change in sensory responsiveness has further consequences for behavioral decisions is an open question.

\subsection{Possible consequences for learning performance and foraging behavior}

It has been shown that sucrose responsiveness of 1-week-old bees correlates with their probability of later becoming a pollen, nectar, or water 
forager (Pankiw and Page 2000). Based on our results, we hypothesize that a higher number of hyperthermia-treated bees than of control bees will become nectar foragers later in life, due to their reduced sucrose responsiveness. For the same reasons, it is further conceivable that among the group of nectar foragers, individuals which had received hyperthermia treatment at larval age later become less responsive nectar foragers than control bees.

Nectar comprises different plant sugars and is an important stimulus for honeybees, because it is their main source of carbohydrates. Honeybees need to evaluate the sucrose concentration of a nectar source using their gustatory sense. The sugar concentration of a food resource plays a key role in the decision to return to this nectar source and in the decision to perform a waggle dance to inform nest mates about this resource (Seeley 1995). Thus, a reduced sucrose responsiveness might result in a modified evaluation of a food resource and in a possible neglect of profitable food sources.

Profitability of a nectar source is also assessed by the receiver bees in the hive, which unload foragers faster when they return with nectar of higher quality (Seeley 1989). The unloading time is dependent on the sucrose response threshold of a receiver bee, which, in turn, is modulated by the sugar concentration of nectar circulating in the colony (Pankiw et al. 2004). A reduced sucrose responsiveness of a receiver may thus have direct consequences for the foraging behavior of numerous hive mates. These points suggest that a reduced sucrose responsiveness at foraging stage, induced by short-term hyperthermia at larval stage, might affect important foragingrelated decisions of honeybees. Further experiments have to test this hypothesis.

Sucrose responsiveness further correlates with individual learning performance under laboratory conditions. A low responsiveness normally correlates with a reduced learning performance (Scheiner et al. 2001a, 2001b, 2003, 2005, 2013). Learning performance of free-flying nectar foragers was similarly shown to correlate with their acceptance of high and low sucrose concentrations in the field (Mujagic et al. 2010). Based on our experiments on sucrose responsiveness, we hypothesize a lower learning performance of foragers. This is in direct contradiction to the findings by Tautz et al. (2003) who showed that slightly warmer temperatures
( $36{ }^{\circ} \mathrm{C}$ in the brood nest) can lead to a better shortterm learning performance of adult bees. We conclude that even slight temperature changes (in our case higher temperatures) during larval stage can have very different effects on the learning performance of the bees when they have become foragers. Therefore, the role of temperature shifts during larval development for later learning performance deserves more detailed examination including different temperature regimes.

\subsection{Life span and social organization}

Our results show a significant positive effect of hyperthermia on life span in cages. Bees treated early in larval development (day 1) displayed a significantly enhanced life span in both replicates. Those treated at the beginning of the pupal phase (day 11) showed an enhanced life span in one replicate but not in the other. Hyperthermia thus had a life-enhancing effect on honeybee worker bees confined in cages. It is not surprising that our caged bees generally showed a lower mortality than hive bees, because they were well provided with food and were unable to undertake foraging flights, which typically leads to higher mortality (Visscher and Dukas 1997). This was true for the control bees as well as for the hyperthermia-treated bees. But our experiments provide the first hint that hyperthermia or short-term thermal stress may enhance life span. Interestingly, thermal stress such as was applied in our experiments does not always lead to an enhanced life span in honeybees but can have the opposite effect. This was demonstrated in experiments by Medina et al. (2018) who repeatedly applied thermal stress to larvae of Africanized honeybees, resulting in a reduced life span. The difference in the application of heat stress between both experiments lies in the fact that we only treated larvae with hyperthermia once, while Medina et al. (2018) treated them repeatedly over the course of 1 week. In addition, Medina et al. studied Africanized honeybees, while we investigated a European honeybee subspecies. The number of heat stress applications may be very important for reducing or enhancing life span of honeybee foragers, possibly through differential effects on the expression of heat shock proteins. In fruit flies, heat shock proteins are not only decisive for conferring resistance to heat and 
other stresses but also enhance life span (Morrow and Tanguay 2003). Similar relationships were demonstrated in Caenorhabditis elegans (Cypser and Johnson 2002) and can be assumed for honeybees. In adult honeybees, temperature treatments of 40 and of $45^{\circ} \mathrm{C}$ were shown to induce the expression of different heat shock proteins (Alqarni et al. 2019). We assume that honeybee larvae already possess functional heat shock proteins whose expression might be induced through short-term hyperthermia such as performed in our experiments. The increased expression of heat shock proteins early in larval development may, in turn, enhance life span. Repeated thermal shocks, in contrast, may induce a different effect on gene expression. An alternative explanation for the different results of Medina et al. (2018) and our results is that the adaptation of Africanized honeybees and European honeybee subspecies to different temperatures in the course of evolution may have shaped the response to thermal stress and the expression of heat shock proteins. In fact, the same thermal stress regime induced a differential expression of heat shock proteins in Africanized bees and European honeybee subspecies (Alqarni et al. 2019). The intriguing yet fascinating relationship between thermal stress, heat shock proteins, and life expectancy certainly deserves further attention and requires more controlled studies in the honeybee.

In our experiment, the one-time hyperthermia application may also have been sufficient to upregulate the egg yolk precursor protein vitellogenin, as has been shown by Bordier et al. (2017). This protein plays a major role in the enhanced longevity of queens and worker bees (Corona et al. 2007; Nelson et al. 2007). Also, short-term hyperthermia may have reduced viral loads without increasing stress levels (such as occurs after long-term or repeated thermal stress (Bordier et al. 2017)), thereby enhancing life span.

In contrast to hyperthermia, the effects of reduced temperatures during development appear to be much clearer. Lower temperatures during larval development generally increased mortality (Wang et al. 2016), severely affected behavior (Tautz et al. 2003; Jones et al. 2005; Becher et al. 2009; AbouShaara et al. 2017), and made bees more susceptible to pesticides (Medrzycki et al. 2010) and infestation by parasites (McMullan and Brown 2005).
In honeybees, individual lifespan is strongly affected by the age of first foraging (Rueppell et al. 2007, 2008). The enhanced life span of our hyperthermia-treated bees may therefore coincide with a prolonged time as nurse bees and a later initiation of foraging behavior. The reduced sucrose responsiveness of hyperthermia-treated bees (our first experiment) indeed suggests a slower development from nurse bee into foragers, because sucrose responsiveness increases when nurse bees become foragers (Scheiner et al. 2017a, 2017b; Thamm et al. 2018). We therefore asked whether hyperthermia-treated bees would initiate foraging activity later than control bees using RFID technology. Our data indicate no effect of treatment on the initiation or ending of flight activity. The duration of foraging trips also did not differ between treatment groups. These results suggest that foraging behavior was unaffected by hyperthermia early in development. Our results therefore support the hypothesis that hyperthermia can increase life span without negatively affecting foraging performance and therefore without enhancing the time spent as hive bee.

\section{CONCLUSIONS}

Our data show that hyperthermia has slight side effects on honeybee workers, i.e., a reduced sucrose responsiveness, when brood was heat-shocked very early or late in development. Because we cannot state with certainty that these effects on sucrose responsiveness may affect behaviors such associative learning or food choice by nectar foragers later in life, we suggest treating honeybee brood not during these developmental stages, if possible. This could be achieved by caging the queen for the period prior to hyperthermia treatment to gain brood of known age. Apart from these effects on sucrose responsiveness with unknown consequences for behavioral decisions, we believe hyperthermia treatment is an excellent method for treating honeybee colonies against Varroa destructor mites. We regard the slightly enhanced life expectancy after treatment as a positive side effect, which may not occur in all situations, for example, when brood is treated at different time points compared to our study. Nevertheless, we suggest to perform further studies on the role of temperature shifts during larval development 
to find the optimal hyperthermia treatment regime which reduces the number of Varroa mites drastically while not affecting honeybees.

\section{ACKNOWLEDGMENTS}

We like to thank all of the beekeepers at the Bavarian State Institute for Viticulture and Horticulture, Institute for Bee Research and Beekeeping, for their support and for providing us with the colonies. Further, we would like to thank Felix Schilcher for helping us to analyze the RFID data. We also like to thank the anonymous reviewers of this manuscript who provided valuable advice for improvement.

\section{AUTHOR CONTRIBUTIONS}

$\mathrm{AK}, \mathrm{SB}$, and RS conceived research and designed experiments. AK performed experiments. SB, $\mathrm{AK}, \mathrm{BR}$, and RS analyzed data. AK and RS wrote manuscript. All authors worked at the revision of the manuscript.

\section{FUNDING INFORMATION}

Open Access funding provided by Projekt DEAL.

\section{OPEN ACCESS}

This article is licensed under a Creative Commons Attribution 4.0 International License, which permits use, sharing, adaptation, distribution and reproduction in any medium or format, as long as you give appropriate credit to the original author(s) and the source, provide a link to the Creative Commons licence, and indicate if changes were made. The images or other third party material in this article are included in the article's Creative Commons licence, unless indicated otherwise in a credit line to the material. If material is not included in the article's Creative Commons licence and your intended use is not permitted by statutory regulation or exceeds the permitted use, you will need to obtain permission directly from the copyright holder. To view a copy of this licence, visit http://creativecommons. org/licenses/by/4.0/.

L'hyperthermie à court terme à l'âge larvaire réduit la réactivité au saccharose des abeilles adultes et peut augmenter la durée de vie température / Varroa destructor / comportement des travailleurs / Apis mellifera / RFID

Eine Kurzzeit-Hyperthermie im Larvenalter reduziert die Zucker-Reagibilität adulter Honigbienen und kann die Lebensdauer verlängern

temperatur / Varroa destructor / bienenverhalten / Apis mellifera / RFID

\section{REFERENCES}

Abou-Shaara H.F., Owayss A.A., Ibrahim Y.Y., Basuny N.K. (2017) A review of impacts of temperature and relative humidity on various activities of honey bees. Insect. Soc. 64, 455-463

Alqarni A.S., Ali H., Iqbal J., Owayss A., Smith B.H. (2019) Expression of heat shock proteins in adult honeybee (Apis mellifera L.) workers under hot-arid subtropical ecosystems. Saudi J. Biol. Sci in press

Amdam G.V., Omholt S.W. (2003) The hive bee to forager transition in honeybee colonies: the double repressor hypothesis. J. Theor. Biol. 223 (4), 451-464

Becher M.A., Scharpenberg H., Moritz R.F. (2009) Pupal developmental temperature and behavioral specialization of honeybee workers (Apis mellifera L.). J. Comp. Physiol. A. 195, 673-679

Behrends A., Scheiner R. (2010) Learning at old age: a study on winter bees. Front. Behav. Neurosci. 4, 15

Behrends A., Scheiner R. (2012) Octopamine improves learning in newly emerged bees but not in old foragers. J. Exp. Biol. 215, 1076-1083

Bordier C., Dechatre H., Suchail S., Peruzzi M., Soubeyrand S., Pioz M., Pélissier M., Causer D., Le Conte Y., Alaux C. (2017) Colony adaptive response to simulated heat waves and consequences at the individual level in honeybees (Apis mellifera). Sci. Rep. 7 (1), 3760

Bujok B., Kleinhenz M., Fuchs S., Tautz J. (2002) Hot spots in the bee hive. Naturwissenschaften 89, 299-301

Corona M., Velarde R.A., Remolina S., Moran-Lauter A., Wang Y., Hughes K.A., Robinson G.E. (2007) Vitellogenin, juvenile hormone, insulin signaling, and queen honey bee longevity. PNAS 104 (17), 7128-7133

Cypser J.R., Johnson T.E. (2002) Multiple stressors in Caenorhabditis elegans induce stress hormesis and extended longevity. J. Gerontol. A 57, B109-B114

De Jong D., De Jong P.H., Goncalves L.S. (1982) Weight loss and other damage to developing worker honeybees from infestation with Varroa jacobsoni. J. Apic. Res. 21, 165-167 
DeGrandi-Hoffman G., Spivak M., Martin J. (1993) The influence of temperature on cuticular color of honeybee (Apis mellifera L) queens. Apidol. 24, 101-108

Engels W. (1998) Efficiency of biotechnical control of varroasis, by means of hyperthermia. Apiacta XXXIII, 49-55

Fehler M., Kleinhenz M., Klügl F., Puppe F., Tautz J. (2007) Caps and gaps: a computer model for studies on brood incubation strategies in honeybees (Apis mellifera carnica ). Naturwissenschaften 94 (8), 675-680

Goras G., Tananaki C.H., Gounari S., Dimou M., Lazaridou E., Karazafiris E., Kanelis D., Liolios V., El Taj H.F., Thrasyvoulou A. (2015) Hyperthermia -a non-chemical control strategy against varroa, J Hell Vet Med Soc 66, 4, 249-256

Groh C., Tautz J., Rössler W. (2004) Synaptic organization in the adult honey bee brain is influenced by brood-temperature control during pupal development. Proc. Natl. Acad. Sci. U. S. A. 101, 4268-4273

Harbo J.R. (2000) Heating adult honey bees to remove Varroa jacobsoni. J. Apic. Res. 39, 181-183

Herb B.R., Wolschin F., Hansen K.D., Aryee M.J., Langmead B., Irizarry R., Amdam G.V., Feinberg A.P. (2012) Reversible switching between epigenetic states in honeybee behavioral subcastes. Nat. Neurosci. $15(10), 1371$

Himmer A. (1932) Die Temperaturverhältnisse bei den sozialen Hymenopteren. Biol. Rev. 7, 224-253

Jones J.C., Helliwell P., Beekman M., Maleszka R., Oldroyd B.P. (2005) The effects of rearing temperature on developmental stability and learning and memory in the honey bee, Apis mellifera. J. Comp. Physiol. A. 191, 1121-1129

Ken T., Bock F., Fuchs S., Streit S., Brockmann A., Tautz J. (2005) Effects of brood temperature on honey bee Apis mellifera wing morphology. Acta Zool. Sin. 51 , 768-771

Kleinhenz M., Bujok B., Fuchs S., Tautz J. (2003) Hot bees in empty broodnest cells: heating from within. J. Exp. Biol. 206, 4217-4231

Kovac H., Käfer H., Stabentheiner A., Costa C. (2014) Metabolism and upper thermal limits of Apis mellifera carnica and A. m. ligustica. Apidol. 45, 664-677

Kraus B., Velthuis H.H.W., Tingek S. (1998) Temperature profiles of the brood nests of Apis cerana and Apis mellifera colonies and their relation to varroosis. J. Apic. Res. 37, 175-181

McMullan J.B., Brown M.J.F. (2005) Brood pupation temperature affects the susceptibility of honeybees (Apis mellifera) to infestation by tracheal mites (Acarapis woodi ). Apidol. 36, 97-105

Medina R.G., Paxton R.J., De Luna E., Fleites-Ayil F.A., Medina L.A., Quezada-Euán J.J.G. (2018) Developmental stability, age at onset of foraging and longevity of Africanized honey bees (Apis mellifera L.) under heat stress (Hymenoptera: Apidae). J. Therm. Biol. 74, 214-225
Medrzycki P., Sgolastra F., Bortolotti L., Bogo G., Tosi S., Padovani E., Porrini C., Sabatini A.G. (2010) Influence of brood rearing temperature on honey bee development and susceptibility to poisoning by pesticides. J. Apic. Res. 49, 52-59

Morrow G., Tanguay R.M. (2003) Heat shock proteins and aging in Drosophila melanogaster. Semin. Cell Dev. Biol. 14, 91-99

Mujagic S., Sarkander J., Erber B., Erber J. (2010) Sucrose acceptance and different forms of associative learning of the honey bee (Apis mellifera L.) in the field and laboratory. Front. Behav. Neurosci. 4, 46

Nelson C.M., Ihle K.E., Fondrk M.K., Page R.E. Jr., Amdam G.V. (2007) The gene vitellogenin has multiple coordinating effects on social organization. PLoS Biol. 5 (3), e62

Nunes-Silva P., Hrncir M., Guimarães J.T.F., Arruda H., Costa L., Pessin G., Sinqueira J.O., de Souza P., Imperatriz-Fonseca V.L. (2018) Applications of RFID technology on the study of bees. Insect. Soc. 66, 15-24

OECD (1998) OECD Guidelines for Testing of Chemical Section 2: effects on biotic systems.

Pankiw T., Page R.E. (2000) Response thresholds to sucrose predict foraging division of labor in honeybees Behav. Ecol. Soc. 47, 265-267

Pankiw T., Nelson M., Page R.E., Fondrk M.K. (2004) The communal crop: modulation of sucrose response thresholds of pre-foraging honey bees with incoming nectar quality. Behav. Ecol. Sociobiol. 55, 286-292

Paxton R.J., Klee J., Korpela S., Fries I. (2007) Nosema ceranae has infected Apis mellifera in Europe since at least 1998 and may be more virulent than Nosema apis . Apidol. $38(6), 558-565$

Ramsey S.D., Ochoa R., Bauchan G., Gulbronson C., Mowery J.D., Cohen A., Lim D., Joklik J., Cicero J.M., Ellis J.D., Hawthorne D., vanEngelsdorp D. (2019) Varroa destructor feeds primarily on honey bee fat body tissue and not hemolymph. PNAS 116, 1792-1801

Rosenkranz P. (1987) Temperature treatment of sealed worker brood as a method of controlling Varroatosis. Apidol. 18, 385-388

Rosenkranz P., Aumeier P., Ziegelmann B. (2010) Biology and control of Varroa destructor. J. Invertebr. Pathol. 103, 96-119

Rueppell O., Chandra S.B., Pankiw T., Fondrik M.K., Beye M., Hunt G., Page R.E. (2006) The genetic architecture of sucrose responsiveness in the honeybee (Apis mellifera L.). Genetics 172, 243-251

Rueppell O., Bachelier C., Fondrk M.K., Page R.E. (2007) Regulation of life history determines lifespan of worker honey bees (Apis mellifera L.). Exp. Gerontol. 42, 1020-1032

Rueppell O., Linford R., Gardner P., Coleman J., Fine K. (2008) Aging and demographic plasticity in response to experimental age structures in honeybees (Apis mellifera L). Behav. Ecol. Sociobiol. 62, 1621-1631 
Scheiner R., Erber J. (2009) Sensory thresholds, learning and the division of foraging labor in the honey bee. In Gadau J., Fewell J.H. (Eds.), Organization of Insect Societies-From genomes to socio-complexity (pp. 335-335). Harvard University Press, Cambridge, MA

Scheiner R., Erber J., Page R.E. (1999) Tactile learning and the individual evaluation of the reward in honey bees (Apis mellifera L.). J. Comp. Physiol. A 185, 1-10

Scheiner R., Page R.E., Erber J. (2001a) Responsiveness to sucrose affects tactile and olfactory learning in preforaging honey bees of two genetic strains. Behav. Brain Res. 120, 67-73

Scheiner R., Page R.E., Erber J. (2001b) The effects of genotype, foraging role and sucrose perception on the tactile learning performance of honey bees (Apis mellifera L.). Neurobiol. Learn. Mem. 76, 138-150

Scheiner R., Barnert M., Erber J. (2003) Variation in water and sucrose responsiveness during the foraging season affects proboscis extension learning in honey bees. Apidol. 34, 67-72

Scheiner R., Page R.E., Erber J. (2004) Sucrose responsiveness and behavioral plasticity in honey bees (Apis mellifera ). Apidol. 35, 133-142

Scheiner R., Kuritz-Kaiser A., Menzel R., Erber J. (2005) Sensory responsiveness and the effects of equal subjective rewards on tactile learning and memory of honeybees. Learn. Mem. 12, 626-635

Scheiner R., Abramson C.I., Brodschneider R., Crailsheim K, Farina WM, Fuchs S, Grünewald B, Hahshold S, Karrer M, Koeniger G, Koeniger N, Menzel R, Mujagic S, Radspieler G, Schmickl T, Schneider C, Siegel AJ, Szopek M, Thenius R. (2013) Standard methods for behavioral studies of Apis mellifera. In: Dietemann V, Ellis JD, Neumann P (Hrsg). The COLOSS BEEBOOK: standard methodologies for Apis mellifera research. IBRA Cardiff.

Scheiner R., Entler B.V., Barron A., Scholl C., Thamm M. (2017a) The effects of fat body tyramine level on gustatory responsiveness of honeybees (Apis mellifera) differ between behavioral castes. Front. Syst. Neurosci. 1, 55

Scheiner R., Reim T., Søvik E., Entler B.V., Barron A.B., Thamm M. (2017b) Learning, gustatory responsiveness and tyramine differences across nurse and forager honeybees. J. Exp. Biol. 220, 1443-1450

Schneider P., Drescher W. (1987) The influence of Varroa jacobsoni Oud. on weight at emergence, development of weight and hypopharyngeal glands, and longevity of Apis mellifera L. Apidol. 18, 101-110

Seeley T.D. (1989) Social foraging in honey bees: how nectar foragers assess their colony's nutritional status. Behav. Eco. Sociobiol. 24 (3), 181-199.

Seeley T.D. (1995) The wisdom of the hive. Harvard University Press, Cambridge Mass, London

Stabentheiner A., Kovac H., Brodschneider R. (2010) Honeybee colony thermoregulation-regulatory mechanisms and contribution of individuals in dependence on age, location and thermal stress. PLoS One 5, e8967

Tabor K.L., Ambrose J.T. (2001) The use of heat treatment for control of the honey bee mite, Varroa destructor. Am Bee J 141, 733-736

Tautz J., Maier S., Groh C., Rossler W., Brockmann A. (2003) Behavioral performance in adult honey bees is influenced by the temperature experienced during their pupal development. Proc. Natl. Acad. Sci. U. S. A. $100,7343-7347$

Thamm M., Sturm K., Schlossmann J., Scheiner R. (2018) Levels and activity of cyclic guanosine monophosphate-dependent protein kinase in nurse and forager honeybees. Insect Mol. Biol. 27, 815-823

Visscher P.K., Dukas R. (1997) Survivorship of foraging honey bees. Insect. Soc. 44 (1), 1-5

Wang Q., Xu X., Zhu X., Chen L., Zhou S., Huang Z.Y. et al (2016) Low-temperature stress during capped brood stage increases pupal mortality, misorientation and adult mortality in honey bees. PLoS One 11, e0154547

Publisher's note Springer Nature remains neutral with regard to jurisdictional claims in published maps and institutional affiliations. 